\title{
Psychological Effects of Social Media among Pre-University Adolescences in Bangalore, India
}

\author{
${ }^{1}$ Jenny Ojha, ${ }^{2}$ Sharmila Jayapalan \\ ${ }^{1}$ School of Health and Allied Sciences, Pokhara University, Kaski, Nepal. \\ ${ }^{2}$ Padmashree College of Nursing, Rjivgandhi University of Health Science, Bangalore, India.
}

\begin{abstract}
For feeling safe and developing trust adolescences need a stable and caring environment. Their basic emotional and physical needs must be consistently met. Adolescences those are not properly guided and are not aware of proper use of social media may become distressful and avoid social contact. Some adolescence may also show signs and symptoms of the psychological effect caused by social media. Psychological effects like sleep disorder, sexual problems, attention deficiency, hyperactivity disorder, addiction, eating disorder, anxiety and depression may vary among adolescents as per the exposure of media. This study focused to assess the exposure of social media and its psychological effects among pre-university adolescences in Bangalore, India. This was institutional based cross-sectional descriptive study design. We carried out this study in purposively selected colleges in Bangalore City. We involved 80 adolescences using non-probability convenience sampling technique. We adopted quantitative method and used structured self-administered questionnaire for collecting required information. We consulted supervisors and experts in the field of nursing and medicine to assure content validity of the tools. We performed descriptive as well as inferential statistical analysis using SPSS 20 version for drawing and interpreting the findings. We assessed adolescences knowledge on social media whereas more than half (55.0\%) were average, nearly one third (33.8\%) had high and $11.3 \%$ had low knowledge. Similarly regarding the attitude of adolescents more two-thirds (71.3\%) had constructive attitude, nearly one-third (28.8\%) had positive attitude. The overall mean scores and standards deviations (SD) of knowledge and attitude were 15.11 and 2.38 out of maximum possible score 48 and 48.47 and 4.20 out of maximum possible score 60 . The total scores of knowledge and attitude were statistically significant $(r=0.348, P<0.05)$. We further assessed association of knowledge and attitude with socio-demographic factors. All almost all factors were not found to be associated with knowledge and attitude. Psychological effects of social media among pre-university adolescences in Bangalore, India varied considering their knowledge and attitude. However knowledge and attitude were significantly associated each other. Social media had constructive as well as destructive effect among adolescences. Family and academic institutions should closely monitor the adolescents and focused them on to use social media for academic purpose rather than entertainment.
\end{abstract}

Keywords: Knowledge, attitude, psychological effects of social media, adolescences.

Corresponding author: Jenny Ojha, School of health and allied science, Pokhara University, Kaski, Nepal.

$$
\text { E-mail: Joyfuljenny01@gmail.com }
$$

\section{INTRODUCTION}

The term adolescence is commonly used to describe the transition stage between childhood and adulthood. Adolescence is also equated to both the terms "teenagers" and "puberty." However adolescence is not exclusive to either of these terms. Puberty refers to the hormonal changes that occur in early youth; and the period of adolescence can extend well beyond the teenage years. In fact, there is no one scientific definition of adolescence or set age boundary. There are key development changes that nearly all adolescents experience during their transition from childhood to adulthood.

Currently, the world's adolescences population is 1.2 billion; $87 \%$ of these adolescences live in developing countries. India has the largest national population of adolescences (243 million). Karnataka is the eighth largest state in India in terms of population. According to latest Population Census of India, the total population of Karnataka was 52.73 million and about $21 \%$ of that comprised the adolescent population. The current estimated population of Karnataka is $61,130,704 .^{2}$

Social media are social software which mediates human beings for the communication. When the technologies are in place, social media is accessible communication techniques. Social media became one of the most powerful sources of news updates through platforms such as Twitter, Face-book and Google in 2012. Social media technologies take on many different forms including magazines, internet forums, weblogs, social blogs, micro-blogging, wikis, social networks, podcasts, photographs or pictures, video, rating and social bookmarking. ${ }^{3}$

Social media or "social networking" has almost become part of our daily lives and being tossed around over the past some years. It is like any other media such as newspaper, radio and television but it is far more than just about sharing information and ideas. Social networking tools like Twitter, Face-book and blogs have facilitated in creation and exchange of ideas so quickly and widely than the conventional media. The power 
of define and control a brand is shifting from corporations and institutions to individuals and communities. ${ }^{4}$

Social media may promote various psychological disorders such insomnia, sleep disorders, sexual problems and deviation, attention deficiency hyperactivity disorder, addiction, eating disorder, anxiety and depression. ${ }^{5}$ This study focused to assess the exposure of social media and its psychological effects among pre-university adolescences in Bangalore, India.

\section{MATERIALS AND METHODS}

This was institutional based descriptive cross-sectional study which was conducted among pre university adolescences in Bangalore. We selected a college continently nearby Bangalore city. There were all together 80 pre university students in that college. We adopted census method and distributed selfadministered questionnaire for assessing their knowledge, attitude on the psychological effects of social media and collecting required socio-demographic information. The self administered structured questionnaire consisted of three sections i.e. socio-demographic information, information on knowledge and three points Likert-type scale for assessing the attitude of adolescences. We further divided knowledge section in different sub sections such as general information on social media, psychological effects caused by social media, use of social media and management of psychological effect caused by social media. Before conducting the study, we obtained written permission from college administration. Similarly, we took verbal consent from each student prior to their participation. We assured students about the provided information that will be kept confidentially and maintained anonymity.

\section{Study tools}

The tool consisted of different three sections. First section consisted of socio-demographic information which contained 10 items i.e. age, gender, religion, type of family, class, income of the family, number of siblings, hobbies, habits influenced by social media and average time of media use. The second section focused to assess the knowledge of adolescents regarding psychological effects of social media. This included 24 items in four categories i.e. six items were consisted on general information, seven items were related to psychological effects, four items were on the use of social media and the remaining seven items contained the management of psychological effects of social media

All questions of knowledge sections were responded as binary outcome either on for correct response and zero for remaining responses. The possible score of knowledge related items was zero to 24 . We categorized the range of score into three groups i.e. low $(<50 \%)$, medium (50-75\%) and high $>50 \%$ ). Similarly the Liker-type scale was consisted of three rating categories i.e. agree, undecided and disagree with the marking score three, two and one respectively. The possible score of attitude was zero to 60 which was categorized into three groups i.e. unfavorable $(<50 \%)$, favorable $(50-75 \%)$ and highly favorable $(>75 \%)$. We again categorized in low $(\leq$ median) and high ( $>$ median) both knowledge and attitude considering median values.

\section{Study setting and population}

The study was conducted at a college, Bangalore, Karnataka, India. This college was selected purposively considering geographical proximity, accessibility for conducting and study population. There were only 80 students in grade 11 and 12 and we applied census method and participle all students in this study.

\section{Statistical analysis}

The units of analysis of this study were students. First we calculated frequency and percentage of most demographic variables such as age, gender, religion, type of family, class, income of the family, number of siblings, hobbies, habits influenced by social media, average time of media use. We calculated mean and SD for assessing the level of knowledge and attitude of adolescences regarding the psychological effects of social media. We also applied Pearson's correlation and Chi-square test to correlate socio-demographic characteristics and knowledge and attitude of adolescences regarding psychological effects of social media.

\section{RESULTS}

Among adolescences more than half (55.0\%) had medium knowledge, one-third (33.8\%) good knowledge and $11.3 \%$ had poor knowledge on psychological effects of the social media. Similarly considering the attitude of adolescences on the psychological effect of social media more than twothirds adolescences $(71.3 \%)$ had strong favourable attitude, remaking $(28.8 \%)$ had favourable attitude.

\section{Socio-demographic characteristics of adolescences \\ Table 1: Selected demographic characteristics of adolescences $(\mathrm{n}=\mathbf{8 0})$}

\begin{tabular}{|c|c|c|c|}
\hline Back & und variables & No. & Percent \\
\hline \multicolumn{4}{|c|}{ Age } \\
\hline & $15 \mathrm{yrs}$ & 27 & 33.8 \\
\hline & $16 \mathrm{yrs}$ & 48 & 60.0 \\
\hline & $17 \mathrm{yrs}$ & 5 & 6.3 \\
\hline \multicolumn{4}{|l|}{ Gender } \\
\hline & Male & 35 & 43.8 \\
\hline & Female & 45 & 56.3 \\
\hline \multicolumn{4}{|l|}{ Religion } \\
\hline & Hindu & 75 & 93.75 \\
\hline & Muslim & 4 & 5.0 \\
\hline & Christian & 1 & 1.25 \\
\hline \multicolumn{4}{|c|}{ Type of family } \\
\hline & Nuclear & 64 & 80.0 \\
\hline & Joint & 15 & 18.8 \\
\hline & Extended & 1 & 1.3 \\
\hline
\end{tabular}


Table 2: Selected socio-economic characteristics of adolescences $(n=80)$

\begin{tabular}{|c|c|c|c|}
\hline \multicolumn{2}{|c|}{ Background variables } & No. & Percent \\
\hline \multicolumn{4}{|c|}{ Income of the family } \\
\hline & Below 5000 & 6 & 7.5 \\
\hline & $5001-10000$ & 26 & 32.5 \\
\hline & Above 10000 & 48 & 60.0 \\
\hline \multicolumn{4}{|c|}{ No. of siblings } \\
\hline & Single child & 7 & 8.8 \\
\hline & Two & 64 & 80.0 \\
\hline & More than two & 9 & 11.3 \\
\hline \multicolumn{4}{|l|}{ Hobbies } \\
\hline & Watching movies & 23 & 28.8 \\
\hline & Reading news paper & 20 & 25.0 \\
\hline & Chatting with friends & 9 & 11.3 \\
\hline & Any other & 28 & 35.0 \\
\hline \multicolumn{4}{|c|}{$\begin{array}{l}\text { Habits influenced by social media (Smoking and } \\
\text { drinking) }\end{array}$} \\
\hline & Yes & 1 & 1.3 \\
\hline & No & 79 & 98.7 \\
\hline \multicolumn{4}{|c|}{ Average time on social media } \\
\hline & $2<2$ hour & 54 & 67.5 \\
\hline & $2 \geq$ hours & 26 & 32.6 \\
\hline
\end{tabular}

Table 3: Demographic characteristics and knowledge of adolescences on regarding psychological effects of social media $(\mathbf{n}=\mathbf{8 0})$

\begin{tabular}{|c|c|c|c|c|c|}
\hline \multirow{2}{*}{\multicolumn{2}{|c|}{$\begin{array}{c}\begin{array}{c}\text { Demographic } \\
\text { characteristics }\end{array} \\
\leq \text { Median }\end{array}$}} & \multicolumn{2}{|c|}{ Knowledge } & \multirow{3}{*}{$\chi^{2}$} & \multirow{3}{*}{ p-value } \\
\hline & & \multirow[t]{2}{*}{$>$ Median } & & & \\
\hline \multirow[t]{3}{*}{ Age } & & & & & \\
\hline & $15 \mathrm{yrs}$ & $14(\% ?)$ & 13 & \multirow{2}{*}{$1.35, \mathrm{df}=2$} & \multirow{2}{*}{$\mathrm{p}>0.05$} \\
\hline & $\geq 16 \mathrm{yrs}$ & 31 & 22 & & \\
\hline \multicolumn{6}{|c|}{ Gender } \\
\hline & Male & 23 & 12 & \multirow{2}{*}{$2.26, \mathrm{df}=1$} & \multirow{2}{*}{$\mathrm{p}>0.05$} \\
\hline & Female & 22 & 23 & & \\
\hline \multicolumn{6}{|c|}{ Religion } \\
\hline & Hindu & 42 & 33 & \multirow{2}{*}{$1.85, \mathrm{df}=2$} & \multirow{2}{*}{$\mathrm{p}>0.05$} \\
\hline & Others & 3 & 2 & & \\
\hline \multicolumn{6}{|c|}{ Type of family } \\
\hline & Nuclear & 35 & 29 & \multirow{2}{*}{$0.927, \mathrm{df}=2$} & \multirow{2}{*}{$p>0.05$} \\
\hline & Others & 10 & 6 & & \\
\hline
\end{tabular}

Table 4: Socio-economic characteristics and knowledge of adolescences on regarding psychological effects of social media $(\mathbf{n}=\mathbf{8 0})$

\begin{tabular}{|c|c|c|c|c|c|}
\hline \multirow{2}{*}{\multicolumn{2}{|c|}{$\begin{array}{l}\begin{array}{l}\text { Socio-economic } \\
\text { characteristics }\end{array} \\
\leq \text { median }\end{array}$}} & \multicolumn{2}{|c|}{ Knowledge } & \multirow[b]{2}{*}{$\chi^{2}$-value } & \multirow[b]{2}{*}{ p-value } \\
\hline & & \multicolumn{2}{|l|}{$>$ median } & & \\
\hline \multicolumn{6}{|c|}{ Income per month (in Rs) } \\
\hline & $\leq 10000$ & 21 & 11 & \multirow{2}{*}{$\begin{array}{l}2.71 \\
\mathrm{df}=2\end{array}$} & \multirow{2}{*}{$\mathrm{p}>0.05$} \\
\hline & $>10000$ & 24 & 24 & & \\
\hline \multicolumn{6}{|l|}{ No. of siblings } \\
\hline & $\leq$ Two & 40 & 31 & \multirow{2}{*}{$\begin{array}{l}0.27 \\
\mathrm{df}=2\end{array}$} & \multirow{2}{*}{$\mathrm{p}>0.05$} \\
\hline & $>$ Two & 10 & 4 & & \\
\hline \multicolumn{6}{|c|}{ Habits influenced by social media (Smoking and drinking) } \\
\hline & Yes & 1 & 1.3 & & \\
\hline & No & 79 & 98.7 & & \\
\hline \multicolumn{6}{|l|}{ Average time } \\
\hline & $\leq 1$ hour & 27 & 27 & \multirow{2}{*}{$\begin{array}{l}1.31 \\
\mathrm{df}=2\end{array}$} & \multirow{2}{*}{$\mathrm{p}>0.05$} \\
\hline & $>$ 1hour & 14 & 12 & & \\
\hline
\end{tabular}

Table 5 Demographic characteristics and attitude of adolescences on regarding psychological effects of social media $(\mathbf{n}=80)$

\begin{tabular}{|c|c|c|c|c|c|}
\hline \multirow{2}{*}{\multicolumn{2}{|c|}{$\begin{array}{l}\text { Demographic variables } \\
\text { smedian }\end{array}$}} & \multicolumn{2}{|l|}{ Attitude } & \multirow[t]{2}{*}{$\chi^{2}$-value } & \multirow[t]{2}{*}{ p-value } \\
\hline & & \multicolumn{2}{|l|}{$>$ median } & & \\
\hline Age & & & & \multirow{3}{*}{$\begin{array}{l}0.271 \\
\mathrm{df}_{=} 2\end{array}$} & \multirow{3}{*}{$\mathrm{p}>0.05$} \\
\hline & $\leq 15 \mathrm{yrs}$ & 25 & 14 & & \\
\hline & $>15 \mathrm{yrs}$ & 22 & 35 & & \\
\hline \multicolumn{6}{|l|}{ Gender* } \\
\hline & Male & 22 & 13 & \multirow{2}{*}{$\begin{array}{l}3.85 \\
\mathrm{df}_{=} 1\end{array}$} & \multirow{2}{*}{$\mathrm{p}<0.05$} \\
\hline & Female & 19 & 26 & & \\
\hline \multirow[t]{2}{*}{ Religion } & Hindu & 39 & 36 & & \\
\hline & Others & 2 & 3 & & \\
\hline \multicolumn{6}{|c|}{ Type of family } \\
\hline & Nuclear & 33 & 31 & \multirow{2}{*}{$\begin{array}{l}1.080 \\
\mathrm{df}_{=} 2\end{array}$} & \multirow{2}{*}{$\mathrm{p}>0.05$} \\
\hline & Others & 8 & 8 & & \\
\hline
\end{tabular}

$* \chi^{2}$ test significant at $\mathbf{p}=\mathbf{0 . 0 5}$ )

Table 6: Socio-economic characteristics and attitude of adolescences on regarding psychological effects of social media $(n=80)$

\begin{tabular}{|c|l|l|l|l|l|}
\hline \multirow{2}{*}{$\begin{array}{c}\text { Socio-economic } \\
\text { characteristics } \leq \text { median }\end{array}$} & \multicolumn{2}{|c|}{ Attitude } & $\chi^{2}$-value & p-value \\
\cline { 2 - 6 } & $>$ median & \multicolumn{2}{|l|}{} & \\
\hline Income of the family & & & & \\
\hline & $\leq 10000$ & 19 & 13 & $\begin{array}{l}3.106, \\
\mathrm{df}=2\end{array}$ & $\mathrm{p}>0.05$ \\
\hline & $>10000$ & 14 & 26 & \\
\hline
\end{tabular}




\begin{tabular}{|l|l|l|l|l|l|}
\hline No. of siblings & & & & \\
\hline & $\leq$ Two & 35 & 35 & $\begin{array}{l}0.276, \\
\mathrm{df}=2\end{array}$ & $\mathrm{p}>0.05$ \\
\hline & $>$ Two & 5 & 5 & & \\
\hline $\begin{array}{l}\text { Habits influenced by social media (Smoking and } \\
\text { drinking) }\end{array}$ & \\
\hline \multicolumn{7}{|l|}{ Yes } & 0 & 1 & & \\
\hline \multicolumn{7}{|l|}{ No } & 41 & 38 & & \\
\hline Average time on social media & $\leq 1$ hour & 27 & 27 & 1.31, & \\
\hline & $>1$ hour & 14 & 12 & $\mathrm{df}=2$, & \\
\hline
\end{tabular}

The knowledge of adolescences regarding psychological effects of social media was found significantly correlated $(\mathrm{r}=0.348, \mathrm{p}<0.05)$ with their attitude. However almost all socio-demographic and socio-economical characteristics of adolescences were found not significantly associated with their knowledge and attitude level.

\section{DISCUSSION}

This study aimed to assess knowledge and attitude of adolescences on social media and its psychological effects among pre-university adolescences in Bangalore, India. We found the knowledge and attitude of adolescences regarding psychological effects of social media significantly correlated $(\mathrm{r}=0.348, \mathrm{p}<0.05)$. However we did not found almost all socio-demographic and socioeconomical characteristics of adolescences significantly associated with their knowledge and attitude level.

The majority $(60.0 \%)$ adolescences were of age 16 years, $56.3 \%$ of them were female, $43.8 \%$ of them were Hindu, $80.0 \%$ were lived in nuclear family, $80.0 \%$ of them had two siblings, almost adolescences had not drinking and smoking habit, nearly two-thirds $(67.5 \%)$ of them used social media less than 1 hour per day. Considering economic status $60.0 \%$ adolescences' family had more than 10000 rupees income per month.

More than half adolescences had medium level knowledge and highly favourable attitude towards psychological effects of social media. However the level of knowledge and attitude varied considering their demographic and socio-economic characteristics. This finding is supported by a e study that was conducted to examine the general information on innovative approaches of using new media with regard to the health promotion of adolescences in New York city of United States which concluded that access of technology among adolescences and young adults should focus on integrating new media into clinical and health education settings. ${ }^{6}$

Similarly next qualitative study to explore a documentary that depicts individuals with schizophrenia can reduce psychiatric stigma which showed that a media depiction of persons with schizophrenia can reduce stigma. ${ }^{7}$

The level of knowledge and attitude of adolescences were found significantly associated with the psychological effects of social media. A quasi experimental study to assess the relationship between adolescents' knowledge and attitudes toward sexual behaviour and media portrayals of sex, among 532 adolescents by using media literacy curriculum focused on sexual portrayals in the media which established a significant relationship between adolescents' decisions and their attitudes toward sexual behaviour and use of social media. It further showed that media literacy had promise as part of a sex education program by providing adolescents with a cognitive framework necessary to understand and resist the influence of media on their decision making concerning sex. ${ }^{8}$

An exploratory study to identify adolescents' attitudes regarding online friendship and internet addiction in Czech Republic revealed that effects between Internet addiction and approaches to friendship may be reciprocal. Being oriented toward having more online friends, preferring online communication, and spending more time online were related to increased risk of internet addiction; on the other hand, there is an alternative causal explanation that internet addiction and preference for online communication conditions young people's tendency to seek friendship from people met online. ${ }^{9}$ This finding also supports the our findings.

Despite the population based cross-sectional study, this study reports only quantitative information. It is a comprehensive subjective phenomenon thus quantitative information may need qualitative explanation for its precise assessment. Similarly, due to constraints of time, and financial and physical resources, we covered small study population. All findings are based on the reported information of respondents. Considering the limited size of the target population at selected college level, we followed census method for recruiting the respondents at college level. Hence study missed the chances of sampling and randomization of participants.

\section{CONCLUSION}

The level of knowledge and attitude towards psychological effects of social media among pre-university adolescents in Bangalore, India is significantly associated. However both knowledge and attitude were not significantly associated with demographic and socio-economic characteristics. Social media may have constructive as well as destructive effect among adolescents. Family and academic institutions should closely monitor the adolescents and focused them to use social media for academic purpose rather than entertainment. 


\section{ACKNOWLEDGEMENTS}

I express my sincere appreciation to all the respondents who participated in the study. My sincere gratitude goes to Rajiv Gandhi University of Health Science, Bangalore, India for granting the permission for the study. I also thank Dr. Tulsi Ram Bhandari, Faculty of Health Sciences, Pokhara University, Nepal, for his comments on the manuscript.

\section{REFERENCES}

1. Reinherz HZ, Paradis AD, Giaconia RM, Stashwick CK, Fitzmaurice G. Childhood and adolescent predictors of major depression in the transition to adulthood. American Journal of Psychiatry, 2003;160(12):2141-7.

2. Patel V, Chatterji S, Chisholm D, Ebrahim S, Gopalakrishna G, Mathers C, Mohan V, Prabhakaran D, Ravindran RD, Reddy KS. Chronic diseases and injuries in India. The Lancet, 2011; 377(9763):413-28.

3. Kaplan Andreas M, Michael H. Users of the world, unite! The challenges and opportunities of social media. Business Horizons, 2010; 53 (13):61.

4. Tay R. Mass media campaigns reduce the incidence of drinking and driving. Evidence-Based Healthcare and Public health, 2005; 9(1):26-9.

5. Beirut. Social media \& mental health: are our minds safe? Thought picks, 2009 August 19. Available from: URL: http:// www.blog.thoughtpick.com/.../social-media-mental-health-are-our-minds-s...

6. Hyden C, Cohall A. Innovative approaches to using new media and technology in health promotion for adolescents and young adults. Adolesc Med State Art Rev, 2011 Dec; 22(3):498-520.

7. Penn DL, Chamberlin C, Mueser KT. The effects of a documentary film about schizophrenia on psychiatric stigma. Schizophr Bull, 2003; 29(2):383-91.

8. Pinkleton BE, Austin EW, Cohen M, Chen YC, Fitzgerald E. Effects of a peer-led media literacy curriculum on adolescents' knowledge and attitudes toward sexual behavior and media portrayals of sex. Health Commun, 2008 Sep; 23(5):462-72.

9. Smahel D, Brown BB, Blinka L. Associations between online friendship and Internet addiction among adolescents and emerging adults. Dev Psychol, 2012 Mar; 48(2):381-88. 